Erkki Koskela* and Mikko Puhakka**

\title{
Stabilizing Competitive Cycles with Distortionary Taxation****
}

Department of Economics, University of Helsinki

Discussion Papers No 560:2003

ISSN 1459-3696

IBSN 952-10-0701-x

April 22, 2003.

* Department of Economics P.O. Box 54, FIN-00014 University of Helsinki, Finland. Email: erkki.koskela@ helsinki.fi.

** Department of Economics, P.O. Box 4600, FIN-90014 University of Oulu, Finland. Email: mikko.puhakka@ oulu.fi.

*** We thank the Research Unit of Economic Structures and Growth (RUESG), the University of Helsinki, for financial support. 


\begin{abstract}
We utilize a simple overlapping generations model with a balanced budget rule to study the effect of distortionary taxation on cycles and local stability of equilibria. We show that under proportional taxation there is a critical tax rate above which cycles will vanish, while in the case of linearly progressive taxation there is a critical level of exemption below which cycles will vanish as well. Hence, a sufficiently high tax rate and a low tax progression eliminate cycles. If the lifetime utility function is quasi-linear, increasing the tax rate can cause the economy to become locally unstable both with proportional and linearly progressive taxation so that tax exemption does not matter. Finally, if the lifetime utility function is not quasi-linear, for small tax rates an increase in progression can locally destabilize the economy.
\end{abstract}

Keywords : overlapping generations, cycles, stabilizing taxation.

JEL classification: D 91, E 32, H 30 


\section{Introduction}

Macroeconomists have long been interested in studying the stabilizing effect of different policies. More than fifty years ago Friedman (1948) advocated a non-discretionary monetary and fiscal framework for stability. It is not, however, always the case that fluctuations are bad for welfare, since the equilibria associated with stable cycles can be efficient. The resulting indeterminacy, however, can be an independent reason for stabilization policy. An appropriate policy can render the equilibrium determinate, and thus possibly rid the economy from the effects of sunspots and bubbles. ${ }^{1}$

The possibility of cycles in simple overlapping generations models was observed by Gale (1973) and Cass, Okuno and Zilcha (1979). Grandmont (1985) elaborated their finding, and analyzed the conditions for the existence of cycles in a precise manner. From the policy point of view Grandmont (1986b) pointed out that simple fiscal and monetary policies involving proportional transfers and lump-sum taxes (or transfers) can abolish the cycles completely. In his demonstration of sunspot equilibria Aiyagari (1988) showed that there is a simple policy of proportional tax rate and lump-sum transfers, which can stabilize the asset price completely, and thus rid the economy from the effects of sunspots. Goenka (1994) advocated a role for discretionary policies in a general equilibrium model with public goods to abolish the sunspot equilibria, and thus stabilize the economy. Ghiglino and Tvede (2000) studied a general overlapping generations model with a prescribed objective function for the government. They showed that if the disc ount factor is close to one, the optimal policy can completely stabilize the economy.

There is a related literature, in which the role of various tax schemes as stabilizing or destabilizing devices has been analysed in models with inefficiencies and/or externalities. It is well known that one-sector real business cycle models with increasing returns to scale may generate cycles driven by animal spirits. Guo and Lansing (1998) showed that a progressive income tax schedule can stabilize the economy against animal spirits type sunspot fluctuations. This is opposite to what happens in an economy with a proportional or regressive tax schedule, when the economy becomes more susceptible to

\footnotetext{
${ }^{1}$ Woodford (1984) provides an excellent exposition of indeterminacy and related issues in overlapping generations models.
} 
indeterminacy. Guo (1999) proved the same result for progressive labour taxation, even when the capital tax rate is proportional. In contrast to these results, Guo and Harrison (2001) have used a twosector real business cycle model with investment externalities to show that a regressive tax policy can stabilize the economy against fluctuations driven by agents' animal spirits, while an economy with a proportional or progressive tax scheme is more prone to sunspot fluctuations.

There is also a recent literature, where tax progression has not been an important issue for stabilization. Schmitt-Grohe and Uribe (1997) showed in a neoclassical growth model that a balanced budget rule may be destabilizing if fiscal policy relies heavily on changes in labour tax rates to achieve budget balance by making higher tax rates selffulfilling. Guo and Lansing (2001) developed a discrete time one-sector growth model with a productive externality to examine numerically the implications of various government fiscal policies for endogenous fluctuations including different types of cycles, quasi-periodic orbits and chaos.

In the real business cycle models, with inefficiencies and/or externalities, summarized briefly above, the stabilizing role of proportional and non-proportional taxes is sensitive to the details of model specifications. In this paper we re-examine these issues in a simple overlapping generations model without inefficiencies or externalities. We do not allow lump sum taxes, but in contrast to Grandmont (1986) and Aiyagari (1988) assume that government must use distortionary taxes to maintain balanced budget. More precisely, we analyse the impact of proportional and linearly progressive taxes on cycles and the local stability of equilibria.

We show the following results. Under proportional taxation the steady state supply exceeds (falls short of) the one without taxation, if the elasticity of the marginal utility of the second period consumption, is higher (lower) than one. This is because the higher (lower) steady state supply in the presence of taxation is due to the fact that the positive income effect of the tax rate dominates (is dominated by) the negative substitution effect. In the presence of cycles, there is a critical level of tax rate above which there are no cycles. Under progressive taxation the steady state supply is less than the one with proportional taxation due to the negative income effect of tax exemption on supply. In this case we show that there is a critical level of tax exemption, such that for 
all tax exemptions below that level there are no cycles in the economy. Hence, a sufficiently high tax rate and a low tax progression eliminate cycles.

We also characterize the effects of tax policy on the local stability of equilibria, and show the following results. First, if the lifetime utility function is quasi-linear, increasing the tax rate can cause the economy to become locally unstable both with proportional and linearly progressive taxation so that tax exemption does not matter. This is because the income effect of tax exemption is zero for consumption. Second, if the lifetime utility function is not quasi-linear, we show that for small tax rates an increase in progression can locally destabilize the economy.

We proceed as follows. In section 2 we present an overlapping generations model with a balanced budget fiscal policy. Section 3 characterizes competitive equilibrium with proportional taxation, the relationship between the level of taxes and cycles, and the impact of tax policy on the local stability of equilibria. In section 4 we ask what are the implications of linearly progressive taxation on cycles and local stability. Finally there is a concluding section.

\section{An Overlapping Generations Model with Fiscal Policy}

We consider a simple overlapping generations model without population growth, with perfect foresight, and a constant stock of money. Producer-consumers consume when old and produce when young. The person born at $t$ has the following additively separable lifetime utility function

$$
U\left(c_{t+1}, n_{t}\right)=u\left(c_{t+1}\right)-v\left(n_{t}\right),
$$

where $c_{t+1}$ denotes consumption when old, and $n_{t}$ labor supply in youth. Labor is transformed to output, $y_{t}$, in a linear fashion so that $y_{t}=n_{t}$, while $u(c)$ is an increasing strictly concave function, and $v(n)$ an increasing strictly convex function. We denote the upper bound for the available time by $\bar{L}$, and make the following assumptions: $\lim _{c \rightarrow 0} u^{\prime}(c)=+\infty, \frac{\lim }{c \rightarrow \infty} u^{\prime}(c)=0, \frac{\lim _{n \rightarrow 0}}{n \rightarrow}(n)=0$ and $\frac{\lim }{n \rightarrow \bar{L}} v^{\prime}(n)=+\infty$. Given our assumptions it follows that $v^{\prime}(0) / u^{\prime}(0)<1$. This means that the slope of the indifference 
curve at the endowment point is less than unity. This assumption is needed for monetary equilibria in this model. Using the terminology in Gale (1973) we have here a Samuelson case.

We consider a simple fiscal policy with a balanced budget, where government taxes the output (income) produced by the young, and uses the proceeds to buy output from the market. We study the potential effects of taxation both in terms of the relationship between tax level and cycles as well as in terms of local stability of equilibria, and compare the results of proportional taxation with those of progressive taxation.

To study the effects of progressive taxation in a simple manner we assume that there is a nominal exemption on the taxable income and a constant marginal tax rate, i.e. $\tau_{t}=\tau \forall t .^{2}$ Total tax revenues in period $t$ are thus

(2) $T_{t}=\tau\left(p_{t} n_{t}-E_{t}\right)$,

where $p_{t} n_{t}$ is the nominal tax base (i.e. price times output of the young), and $E_{t}$ denotes the nominal exemption, which we assume to be constant as well, i.e. $E_{t}=E \forall t$. The average tax rate equals $T_{t} / p_{t} n_{t}=\tau\left(1-\frac{E}{p_{t} n_{t}}\right)$, which is less than the marginal tax rate $\tau$.

The tax schedule (2) is progressive in the sense that even though the marginal tax rate is constant, the average tax rate increases with the tax base. ${ }^{3}$ An increase in the average tax rate is higher the higher is the marginal tax rate and tax exemption when the tax base goes up.

The government budget constraint in the absence of debt financing is

$$
p_{t} g_{t}=T_{t}=\tau\left(p_{t} n_{t}-E\right)
$$

We emphasize that the real government expenditure, $g_{t}$, is not a given sequence, but it adjusts every period to the level necessary to maintain balanced budget.

With proportional taxation the government budget constraint is

\footnotetext{
${ }^{2}$ For the definition of progressive taxation, see the seminal paper by Musgrave and Thin (1948). See also Lambert (1993), chapters 6-8, for further analyses, Sandmo (1983) and Koskela and Vilmunen (1995) for various applic ations.

${ }^{3}$ Guo and Lansing $(1998,2001)$ parametrize tax progression such that both the marginal and average tax rates will increase with the tax base. See also Guo (1999) and Guo and Harrison (2001).
} 


$$
g_{t}=\tau n_{t} .
$$

\section{Competitive Equilibrium with Proportional Taxation}

In this section we provide the answers to the following questions. First, under what conditions are there cycles in the model? Second, can the proportional taxation eliminate cycles. And third, what is the effect of the tax rate on the local stability of equilibrium.

We first study the properties of competitive equilibrium in the presence of proportional taxation. The private sector periodic budget constraints are

$$
p_{t}(1-\tau) n_{t}=M_{t}^{d}
$$

$$
p_{t+1} c_{t+1}=M_{t}^{d},
$$

from where we have the lifetime constraint as

(6) $\quad c_{t+1}=\frac{p_{t}(1-\tau)}{p_{t+1}} n_{t}$.

The young producers accumulate money by selling their output to the old, and part of it to the government. The first-order condition for the utility maximization subject to budget constraints (5i) and (5ii) is

$$
\frac{p_{t}(1-\tau)}{p_{t+1}} u^{\prime}\left(\frac{p_{t}(1-\tau)}{p_{t+1}} n_{t}\right)=v^{\prime}\left(n_{t}\right)
$$

The solution to (7) gives the young's supply function $n_{t}=n\left(\frac{p_{t}(1-\tau)}{p_{t+1}}\right)$. If supply is increasing in the after tax real wage $\left(p_{t}(1-\tau) / p_{t+1}\right)$, a rise in the tax rate will decrease supply, while the reverse happens if supply is downward sloping.

The equilibrium condition for the goods market is

$$
\frac{M_{t-1}^{d}}{p_{t}}+g_{t}=n_{t}
$$

Taking into account the government budget constraint, (4), and the fact that the nominal money supply is constant, we rewrite (8) as

$$
\frac{M}{p_{t}}=(1-\tau) n_{t}
$$


Using equation (9) in the first-order condition (7) we can re-express it as

$$
(1-\tau) n_{t+1} u^{\prime}\left[(1-\tau) n_{t+1}\right]=n_{t} v^{\prime}\left(n_{t}\right)
$$

This equation determines the equilibrium sequence of supplies for a given tax rate, and implicitly defines the reflected generational offer curve. ${ }^{4}$

If the second period utility function, $u\left(c_{t+1}\right)$, is logarithmic, the proportional tax rate will have no effect on the equilibrium sequence. The dynamics is then determined from the condition $n_{t} v^{\prime}\left(n_{t}\right)=1$, so that the economy stays forever at the steady state, $\hat{n}$, determined from $\hat{n} v^{\prime}(\hat{n})=1$.

In order to explore the impact of fiscal policy we first ask: How does the steady state solution to (10) (denoted by $\hat{n}$ ) compare to the steady state supply without proportional taxation, $n *$. The answer is given in

Proposition 1. Under proportional taxation the steady state supply exceeds (falls short of) the one without taxation, if the elasticity of the marginal utility of the second period consumption (or the Arrow-Pratt measure of the relative risk aversion), denoted by $\sigma$, is higher (lower) than one, i.e.

$$
\hat{n}\left\{\begin{array}{l}
> \\
= \\
<
\end{array}\right\} n^{*} \text { as } \sigma\left\{\begin{array}{l}
> \\
= \\
<
\end{array}\right\} 1 \text {. }
$$

Proof: Rewriting equation (10) in the steady state as $\operatorname{LHS}(n ; \tau) \equiv(1-\tau) u^{\prime}[(1-\tau) n]=v^{\prime}(n) \equiv \operatorname{RHS}(n)$ and given the Inada conditions we have $R H S(0)=0$ and $\frac{\lim }{n \rightarrow \bar{L}} R H S(n)=\infty$, and $R H S^{\prime}(n)>0$. We also have $L H S_{n}(n ; \tau)<0$. We calculate $\quad L H S_{\tau}(n ; \tau)=-u^{\prime}[(1-\tau) n]-(1-\tau) n u^{\prime \prime}[(1-\tau) n], \quad$ and $\quad$ re-express $L H S_{\tau}(n ; \tau)=-u^{\prime}[(1-\tau) n](1-\sigma(n))$, where $\sigma(n)=-(1-\tau) n u^{\prime \prime}[(1-\tau) n] / u^{\prime}[(1-\tau) n]$. Note that consumption in steady state is $(1-\tau) n$. When $\sigma(n)>1$, the curve $L H S(n ; \tau)$ shifts up, if the tax rate is raised. The results of Proposition 1 follow from this observation. Q.E.D.

\footnotetext{
${ }^{4}$ The geometric techniques of the reflected generational offer curves, developed by Cass, Okuno and Zilcha (1979), are useful in characterizing properties of equilibria in many overlapping generations models.
} 
Proposition 1 follows from a property of the Slutsky equation. The higher (lower) steady state supply with than without taxation is due to the fact that the positive income effect of the tax rate dominates (is dominated by) the negative substitution effect. The Slutsky equation can be written as $n_{\tau}=n_{\tau}^{c}-n n_{m}$, where $n_{\tau}^{c}$ is the negative substitution effect and $-n n_{m}$ the positive income effect. The latter (former) effect - evaluated at $m=0$ - dominates if $\sigma(n)>(<) 1$. (for a precise elaboration of this intuition, see Appendix).

We differentiate (10) to get

$$
\frac{d n_{t+1}}{d n_{t}}=\frac{v^{\prime}\left(n_{t}\right)+n_{t} v^{\prime \prime}\left(n_{t}\right)}{(1-\tau) u^{\prime}\left[(1-\tau) n_{t+1}\right]+(1+\tau)^{2} n_{t+1} u^{\prime \prime}\left[(1-\tau) n_{t+1}\right]} .
$$

We drop the subscripts and note that the second period consumption equals $(1-\tau) n$. Equation (11) cannot be signed generally since the sign of the denominator is a priori ambiguous. Defining $D(n)=(1-\tau)\left\{u^{\prime}[(1-\tau) n]+(1-\tau) n u^{\prime \prime}[(1-\tau) n]\right\}$ we can express it as

$$
D(n)=(1-\tau) u^{\prime}((1-\tau) n)\left[1+\frac{(1-\tau) n u^{\prime \prime}[(1-\tau) n]}{u^{\prime}[(1-\tau) n]}\right]
$$

Defining the elasticity of the marginal utility of the second period consumption (or the Arrow-Pratt measure of the relative risk aversion) as $\sigma(n)=-\left[(1-\tau) n u^{\prime \prime}((1-\tau) n) / u^{\prime}((1-\tau) n)\right]$, and using it we can rewrite equation (12) as $D(n)=u^{\prime}(n)[1-\sigma(n)]$. Thus we see that $D(n)>0$, when $\sigma(n)<1$. This means that it is necessary for backward bending offer curve (and indeed for cycles) to have $\sigma(n)>1 .^{5}$

To explore the stabilizing effect of proportional taxation on cycles we use the following notation in equation (10) above

$$
U[n ; \tau] \equiv(1-\tau) n u^{\prime}[(1-\tau) n] \text { and } G(n) \equiv n v^{\prime}(n) .^{6}
$$

Since function $G(n)$ is monotone increasing we can invert it, and obtain from (13) the following relation

$$
n_{t}=G^{-1}\left(U\left[n_{t+1} ; \tau\right]\right) \equiv \Phi_{\tau}\left(n_{t+1}\right)
$$

\footnotetext{
${ }^{5}$ This is well known since the seminal paper by Grandmont (1985).

${ }^{6}$ To explore this issue we follow Grandmont (1986), and partly Aiyagari (1988).
} 
which is actually the inverted reflected generational offer curve. Note that this equation describes the backward perfect foresight dynamics of equilibrium. The reason for studying backward dynamics here is because the properties of $\Phi_{\tau}\left(n_{t+1}\right)$ are easier to relate to the shape of the reflected generational offer curve than to the respective curve for backward bending forward dynamics. If there is no subscript in the RHS of (14) it then refers to the case without taxation.

To make this problem interesting from the point of view of cycles and the effect of policies on them we assume that there can be cycles in our model economy. For the existence of a two cycle (or a periodic point with period two) it is necessary that function $\Phi(n)$ (economy without taxation) is downward sloping. That property, however, is not sufficient for periodic solutions of higher order. To have periodic points with period three and more, it is necessary that the curve, $n_{t}=\Phi\left(n_{t+1}\right)$, must be hump-shaped. And more precisely, if there are three cycles in the economy without taxation (see Figure 1), there must, according to Sarkovskii's theorem, be periodic solutions of any order higher than three. ${ }^{7}$ It is also well known that cycles in overlapping generations models are intimately connected with sunspot equilibria. ${ }^{8}$ Below we present a parametric specification of our model and provide conditions under which we get a hump-shaped offer curve.

Next we ask: Is there a proportional tax policy, which can eliminate cycles? We provide a positive answer in the following proposition.

Proposition 2 There is a critical level of the proportional tax rate, $\hat{\tau}$, such that for all $\tau>\hat{\tau}$, there are no cycles in the economy.

Proof: Let $n^{\prime}$ be the maximum of the function $\Phi(n)$ such that $\Phi\left(n^{\prime}\right)>n^{\prime}$. We see that the maximum for the function $\Phi_{\tau}(n)$ is at $n^{\prime} /(1-\tau)$. The maximizing point of $\Phi_{\tau}\left(n_{t+1}\right)$ can then be increased in such a way that ultimately we have for some $\tau$, say $\hat{\tau}$,

\footnotetext{
${ }^{7}$ An elementary discussion and elaboration of Sarkovskii's theorem can be found e.g. in Holmgren (1996), see in particular chapter 5 . On the conditions for the existence of cycles of more than two periods in economic models, see Grandmont (1986b).

${ }^{8}$ Azariadis and Guesnerie (1986) showed that a two cycle is enough for the existence of a stationary sunspot equilibrium. Their results were partly refined by Chattopadhyay and Muench (1999).
} 
that $\Phi_{\tau}\left[n^{\prime} /(1-\hat{\tau})\right]<n^{\prime} /(1-\hat{\tau})$. It follows that $1>\Phi_{\tau}{ }^{\prime}(\hat{n})>0$, where $\hat{n}$ is the respective steady state, which in turn means that there can be no cycles. Q.E.D.

Hence, according to Proposition 2 a sufficiently high proportional tax rate will eliminate cycles by changing the location and slope of the inverted reflected generational offer curve. In Figure 1 we have described an economy without taxation but with cycles (curve $n_{t}=\Phi\left(n_{t+1}\right)$ ) and an economy with proportional taxation, and with such a policy that there can be no cycles (curve $n_{t}=\Phi_{\tau}\left(n_{t+1}\right)$ ). In the latter case the tax rate is high enough to suppress the cycles. The steady state is stable in backward dynamics, and is denoted by $\hat{n}$ in Figure 1.

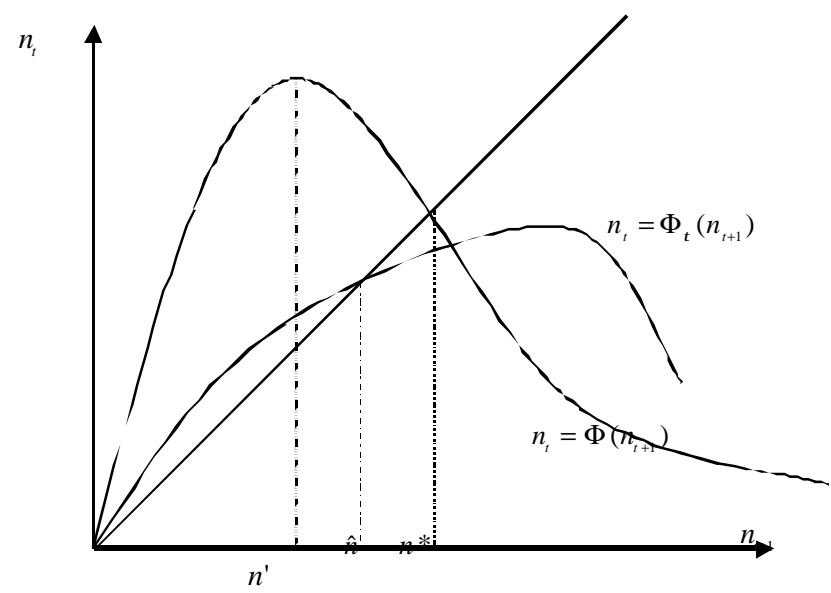

Figure 1.

To be able to study more precisely the relationship between proportional taxation, cycles and local stability of equilibrium, we consider a parametric example, which allows for backward-bending reflected generational offer curve. We specify the lifetime quasilinear utility function ${ }^{9}$ as follows: The consumption preferences are described by $u(c)=(c+a)^{1-\sigma} /(1-\sigma)$, where $a$ denotes a relative luxury of consumption ${ }^{10}$, and the

\footnotetext{
${ }^{9}$ Quasi-linearity is often used in the welfare analyses to simplify the presentation, see e.g. Laffont (1988), pp.158-161.

${ }^{0}$ For a further discussion of this specification, see e.g. Auerbach and Hines (2001).
} 
preferences for disutility of labor are linear, $v(n)=n$. We assume here that $\sigma>1$, which both lies in conformity with empirics ${ }^{11}$, and yields possibly interesting dynamics. Under these specifications the supply function can be written as

$$
n_{t}=R_{t+1}^{\frac{1}{\sigma}-1}(1-\tau)^{\frac{1}{\sigma}-1}-\frac{a}{R_{t+1}(1-\tau)}
$$

where we have used the notation: $R_{t+1}=p_{t} / p_{t+1}$. Differentiating (15) with respect to the interest factor and the tax rate we get

$$
\frac{\partial n_{t}}{\partial R_{t+1}}=(1-\tau)^{-1} R_{t+1}^{-2}\left[\left(\frac{1-\sigma}{\sigma}\right) R_{t+1}^{\frac{1}{\sigma}}(1-\tau)^{\frac{1}{\sigma}}+a\right]
$$

(16ii) $\frac{\partial n_{t}}{\partial \tau}=-(1-\tau)^{-2} R_{t+1}^{-1}\left[\left(\frac{1-\sigma}{\sigma}\right) R_{t+1}^{\frac{1}{\sigma}}(1-\tau)^{\frac{1}{\sigma}}+a\right]=-\left(\frac{R_{t+1}}{1-\tau}\right) \frac{\partial n_{t}}{\partial R_{t+1}}$.

These equations show that the interest factor and the tax rate have an opposite effect on supply. Clearly, the supply function can be backward bending with respect to the interest factor, if $\sigma>1$. Hence, given the interest factor, for all the tax rates which fulfill $\tau<1-\left(\frac{\sigma}{\sigma-1}\right)^{\sigma} a^{\sigma} R_{t+1}{ }^{-1}$, the supply function is backward bending with respect to the tax rate. This means that decreasing the tax rate will decrease the supply and vice versa.

Next we analyze the properties of competitive equilibrium for this example with the assumption that $\sigma>1$. Utilizing (10) we get in equilibrium

$$
\frac{(1-\tau) n_{t+1}}{\left[(1-\tau) n_{t+1}+a\right]^{\sigma}}=n_{t}
$$

where we calculate the steady state $\hat{n}=(1-\tau)^{\frac{1}{\sigma}-1}-a /(1-\tau)$. Note that the steady state without taxes is $n^{*}=1-a$. By direct differentiation with respect to the tax rate we can see that $\hat{n}>n^{*}$, if $\sigma>1 .^{12}$ Differentiating (17) we get

$$
\frac{\partial n_{t}}{\partial n_{t+1}}=\frac{(1-\sigma)(1-\tau)^{2} n_{t+1}+(1-\tau) a}{\left[(1-\tau) n_{t+1}+a\right]^{\sigma+1}} .
$$

\footnotetext{
${ }^{11}$ See e.g. a recent survey by Attanasio (1999).

${ }^{12}$ See Proposition 1.
} 
To get the hump-shaped offer curve described in Figure 1, and thus to allow for periodic solutions of order higher than two we need to have the maximum of the offer curve, $a /(\sigma-1)(1-\tau)$, to be less than the steady state, $(1-\tau)^{\frac{1}{\sigma}-1}-a /(1-\tau)$. This will lead to the following inequality for the tax rate $\tau<1-\left(\frac{a \sigma}{\sigma-1}\right)^{\sigma}=\hat{\tau}$. If the tax rate exceeds $\hat{\tau}$, there can be no cycles in this economy as noted in Proposition 2 above.

Finally we explore the local stability of equilibrium. Evaluating the slope of (18) at the steady state yields

$$
\frac{\partial n_{t}}{\partial n_{t+1}}\left(n_{t}=n^{*}\right)=\frac{(1-\sigma)(1-\tau)^{\frac{1}{\sigma}}+\sigma a}{(1-\tau)^{\frac{1}{\sigma}}}
$$

where the numerator should be negative for cycles. Inverting (19) we get the following stability condition for the local forward looking perfect foresight dynamics

$$
\frac{(1-\tau)^{\frac{1}{\sigma}}}{(1-\sigma)(1-\tau)^{\frac{1}{\sigma}}+\sigma a}>-1 .^{13}
$$

We can rewrite it as

$$
\sigma\left[1-\frac{a}{(1-\tau)^{\frac{1}{\sigma}}}\right]-1>1
$$

which implies that the tax rate must fulfill the following inequality $\tau<1-\left(\frac{a \sigma}{\sigma-2}\right)^{\sigma}=\tilde{\tau}$, and $\hat{\tau}>\tilde{\tau}$. According to (21) increasing the tax rate above $\tilde{\tau}$ can make the economy to become unstable. Whether this happens depends also on the magnitudes of the relative luxury of consumption, $a$, and on the elasticity of marginal utility of consumption, $\sigma{ }^{14}$

\footnotetext{
${ }^{13}$ It is important to keep in mind here that we are studying forward dynamics. The result in Proposition 2 was proved by exploring the backward dynamics.
} 


\section{Competitive Equilibrium with Progressive Taxation}

It has been recognized in the earlier literature on fiscal policy that progressive taxation operates as an automatic stabilizer to smooth business fluctuations. ${ }^{15}$ In the real business cycle models, summarized in introduction, the stabilizing role of progressive taxation is sensitive to the details of model specifications. In this section we re-examine this issue in our model and study the effects of linearly progressive taxation from the same perspective as we did for proportional taxation, and compare the results to those presented above.

The private sector periodic budget constraints are now

$$
p_{t}(1-\tau) n_{t}+\tau E=M_{t}^{d}
$$

$$
p_{t+1} c_{t+1}=M_{t}^{d}
$$

so that the lifetime constraint is

$$
c_{t+1}=\frac{p_{t}(1-\tau) n_{t}+\tau E}{p_{t+1}} .
$$

The young producers accumulate money by selling their output again to the old, and part of it to the government. The first-order condition for the utility maximization subject to budget constraints (22i) and (22ii) is

$$
\frac{p_{t}(1-\tau)}{p_{t+1}} u^{\prime}\left(\frac{p_{t}(1-\tau) n_{t}+\tau E}{p_{t+1}}\right)=v^{\prime}\left(n_{t}\right)
$$

which implicitly defines the young's supply function, $n_{t}=n\left(\frac{p_{t}(1-\tau)}{p_{t+1}}, \frac{\tau E}{p_{t+1}}\right)$. The equilibrium condition in the goods market is again

$$
\frac{M_{t-1}^{d}}{p_{t}}+g_{t}=n_{t} .
$$

Taking into account the government budget constraint and the fact that the nominal money supply is constant we can rewrite (25) for periods $t$ and $t+1$ as

$$
M=p_{t}(1-\tau) n_{t}+\tau E, M=p_{t+1}(1-\tau) n_{t+1}+\tau E .
$$

\footnotetext{
${ }^{14}$ This can also be seen by differentiating the left-hand side of equation (21) with respect to the tax rate, and noting that the partial derivative will be negative.
} 
From (26) it follows that $p_{t} n_{t}=p_{t+1} n_{t+1}$, which means that the tax base stays constant also outside the steady states. Now we can develop the first-order condition above as

$$
\frac{(1-\tau) n_{t+1}}{n_{t}} u^{\prime}\left(\frac{M}{p_{t+1}}\right)=v^{\prime}\left(n_{t}\right) .
$$

From (26) we solve $p_{t+1}=\frac{M-\tau E}{(1-\tau) n_{t+1}}$. Plugging this into (27) yields

$$
(1-\tau) n_{t+1} u^{\prime}\left[\frac{(1-\tau) n_{t+1}}{1-\frac{\tau E}{M}}\right]=n_{t} v^{\prime}\left(n_{t}\right)
$$

which determines the equilibrium sequence of supplies. If the second period preferences are logarithmic, the dynamics is determined from the condition $n_{t} v^{\prime}\left(n_{t}\right)=1-\tau E / M$, i.e. the economy stays forever at the steady state, $\tilde{n}$, determined from $\tilde{n} v^{\prime}(\tilde{n})=1-\tau E / M$. It is also interesting to note that the level of nominal money supply affects the intertemporal allocation in the presence of progressive taxation.

Now we ask: How does the steady state solution to (28) (denoted by $\tilde{n}$ ) under progressive taxation compare to the steady state with proportional taxation, $\hat{n}$. The answer is given in

Proposition 3. The steady state supply under progressive taxation is less than the supply with proportional taxation.

Proof: We rewrite equation (28) in the steady state as $\operatorname{LHS}(n ; \tau, E) \equiv(1-\tau) u^{\prime}\left[\frac{(1-\tau) n}{1-\frac{\tau E}{M}}\right]=v^{\prime}(n) \equiv \operatorname{RHS}(n)$. Given the Inada conditions we have $R H S(0)=0$ and $\frac{\lim }{n \rightarrow \bar{L}} R H S(n)=\infty$, and $R H S^{\prime}(n)>0$. We also have $L H S_{n}(n ; \tau, E)<0$.

\footnotetext{
${ }^{15}$ See e.g. Friedman (1948), Musgrave and Miller (1948) and Slitor (1948).
} 
We calculate $L H S_{E}(n ; \tau, E)=(1-\tau)\left(1-\frac{\tau E}{M}\right)^{-2} \frac{\tau}{M} n u^{\prime \prime}\left[\frac{(1-\tau) n}{1-\frac{\tau E}{M}}\right]<0 \quad$ so that the $\operatorname{LHS}(n ; \tau, E)$ shifts down, when tax exemption is increased. Proposition follows from this finding. Q.E.D.

This proposition is not surprising, since in competitive models progressive taxation is more distortionary than the proportional taxation. A higher level of tax exemption decreases the steady state supply due to the negative income effect of tax exemption on supply.

To explore the stabilizing effect of taxation on cycles we use the following notation in equation $(28)$

$$
\hat{U}[n ; \tau, E] \equiv(1-\tau) n u^{\prime}\left[\frac{(1-\tau) n}{1-\frac{\tau E}{M}}\right] \text { and } \hat{G}(n)=n v^{\prime}(n)
$$

Since function $\hat{G}(n)$ is monotone increasing we can invert it, and obtain from (29) the following relation

$$
n_{t}=\hat{G}^{-1}\left(\hat{U}\left[n_{t+1} ; \tau, E\right]\right) \equiv \Phi_{E}\left(n_{t+1}\right),
$$

which is again the inverted reflected generational offer curve, where subscript $E$ refers to the case of progressive taxation. If there is no subscript in (30), it then refers to the case without taxation. We assume that there is at least a two-cycle in the economy without taxation (see Figure 1). As with proportional taxation the hump-shaped form of equation (30) is not necessary for two cycles, but it is necessary for three cycles. ${ }^{16}$

Next we ask: Is there a progressive tax policy, which can stabilize the economy by eliminating cycles? We provide an answer in the following proposition.

Proposition 4 Given the marginal tax rate there is a critical level of tax exemption, $\hat{E}$, such that for all $E<\hat{E}$, there are no cycles in the economy.

\footnotetext{
${ }^{16}$ See footnote 7 above.
} 
Proof: Let $n^{\prime}$ be the maximum of the function $\Phi(n)$ such that $\Phi\left(n^{\prime}\right)>n^{\prime}$. The maximum for the function $\Phi_{\tau}(n)$ is thus at $n^{\prime} /(1-\tau)$, and for the function $\Phi_{E}(n)$ at $\left(1-\frac{\tau E}{M}\right) n^{\prime} /(1-\tau)$. The maximizing point of $\Phi_{E}\left(n_{t+1}\right)$ can then be increased by decreasing $E$ in such a way that ultimately we have for some $E$, say $\hat{E}$, that $\Phi_{E}\left[\left(1-\frac{\tau E}{M}\right) n^{\prime} /(1-\hat{\tau})\right]<\left(1-\frac{\tau E}{M}\right) n^{\prime} /(1-\hat{\tau})$. This also means that $1>\Phi_{E}^{\prime}(\tilde{n})>0$, where $\tilde{n}$ is the respective steady state, which in turn means that there can be no cycles. Q.E.D.

Hence, according to Proposition 4 a sufficiently low progressive taxation meaning that the average tax rate does not increase with the tax base too quickly - will eliminate cycles.

Next we consider our example specified in section 3 above. Analogously to the derivation of the supply function with proportional taxes (c.f. equation 15) we get

$$
n_{t}=R_{t+1}^{\frac{1}{\sigma}-1}(1-\tau)^{\frac{1}{\sigma}-1}-\frac{a}{R_{t+1}(1-\tau)}-\frac{\tau E}{(1-\tau) p_{t}},
$$

where the term, $E / p_{t}$, is the real exemption. Differentiating (31) with respect to the tax rate, and exemption we get

$$
\frac{\partial n_{t}}{\partial \tau}=-(1-\tau)^{-2} R_{t+1}^{-1}\left[\left(\frac{1-\sigma}{\sigma}\right) R_{t+1}^{\frac{1}{\sigma}}(1-\tau)^{\frac{1}{\sigma}}+a\right]-(1-\tau)^{-2} \frac{E}{p_{t}}
$$

(32ii) $\frac{\partial n_{t}}{\partial E}=-\frac{\tau}{(1-\tau) p_{t}}$.

We find from (32i) that for a given interest factor decreasing the tax rate will decrease the supply (i.e. $\partial n_{t} / \partial \tau>0$ ), if the marginal tax rate and tax exemption fulfill the following condition

$$
\tau \leq 1-\left(\frac{\sigma}{\sigma-1}\right)^{\sigma}\left(\frac{a}{R_{t+1}}+\frac{E}{p_{t}}\right)^{\sigma} R_{t+1}^{\sigma-1} .
$$


Now we analyze the competitive equilibrium for this specification again with the assumption that $\sigma>1$. Using equation (28) we obtain

$$
\frac{(1-\tau) n_{t+1}}{\left[\frac{(1-\tau) n_{t+1}}{1-\frac{\tau E}{M}}+a\right]^{\sigma}}=n_{t},
$$

where we calculate the steady state $\tilde{n}=\left(1-\frac{\tau E}{M}\right)(1-\tau)^{\frac{1}{\sigma}-1}-\left(1-\frac{\tau E}{M}\right) \frac{a}{1-\tau}$. This can be expressed in terms of the steady state with proportional taxation as $\tilde{n}=\left(1-\frac{\tau E}{M}\right) \hat{n}$. Hence, introducing tax exemption, which makes taxation progressive, decreases the steady state supply compared to the case with proportional taxation (see Proposition 3).

Differentiating (34) yields

$$
\frac{\partial n_{t}}{\partial n_{t+1}}=\frac{\frac{(1-\sigma)(1-\tau)^{2} n_{t+1}}{1-\frac{\tau E}{M}}+(1-\tau) a}{\left[\frac{(1-\tau) n_{t+1}}{1-\frac{\tau E}{M}}+a\right]^{\sigma+1}} .
$$

Evaluating the slope at the steady state we get

$$
\frac{\partial n_{t}}{\partial n_{t+1}}\left(n_{t}=\tilde{n}\right)=\frac{(1-\sigma)(1-\tau)^{\frac{1}{\sigma}}+\sigma a}{(1-\tau)^{\frac{1}{\sigma}}},
$$

where the numerator must be negative. Inverting (36) and rearranging we get the stability condition for the local forward looking perfect foresight dynamics to be

$$
\sigma\left[1-\frac{a}{(1-\tau)^{\frac{1}{\sigma}}}\right]-1>1 \text {. }
$$

According to (37) increasing the tax rate can cause the economy to become unstable, i.e. if $\tau$ increases enough the inequality sign might turn around depending on 
the relative size of parameters $a$ and $\sigma .{ }^{17}$ Note that this condition is exactly the same (c.f. equation (21)) as with the presence of proportional taxation. This is due to the quasilinear specification of the lifetime utility function, which is strictly concave in consumption and linear in leisure and labor supply. Therefore the income effect of tax exemption is zero for consumption.

Finally we consider an example where - unlike in the case of quasi-linear utility function - the income effect for consumption is not zero. We assume that disutility function $(v(n))$ is of the form $v(n)=(1 / 4) n^{2}{ }^{18}$, which gives the following equilibrium dynamics

$$
\frac{(1-\tau) n_{t+1}}{\left[\frac{(1-\tau) n_{t+1}}{1-\frac{\tau E}{M}}+a\right]^{\sigma}}=\frac{1}{2} n_{t}^{2}
$$

While we cannot explicitly solve for the steady state, we, however, get from (38) the following relation at the steady state

$$
\operatorname{LHS}(n ; \tau, E, M) \equiv\left[\frac{(1-\tau) n}{1-\frac{\tau E}{M}}+a\right]^{\sigma}=\frac{2(1-\tau)}{n} \equiv \operatorname{RHS}(n ; \tau) .
$$

The left-hand side of (39) is an increasing, and the right-hand side a decreasing function of supply, $n$. Furthermore, we see from (39) that $\left.{ }^{2} H S_{E}(n ; \tau, E, M)\right)>0$. This means that an increase in the level of exemption will shift the $\operatorname{LHS}(n ; \tau, E, M)$ curve up, so that there is a negative relationship between the steady state employment and exemption, i.e. $\partial n / \partial E<0$.

\footnotetext{
${ }^{17}$ This can also be seen by differentiating the left-hand side of (37) with respect to the tax rate, and noting that the partial derivative will be negative.

18 This kind of specification for the disutility function has been used in a different context by Farmer and Woodford (1997).
} 
Using (38) we compute

(40)

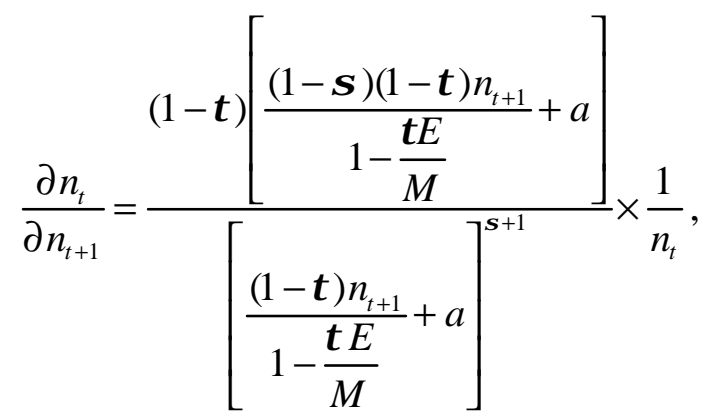

Again we concentrate on the case, where $\sigma>1$, so that the above slope can be negative. Next we evaluate the slope at the steady state. Using (39) and evaluating (40) at the steady state we obtain

$$
\left.\frac{\partial n_{t}}{\partial n_{t+1}}\right|_{n_{t}=n^{*}}=\frac{\left[\frac{(1-\tau) n}{1-\frac{\tau E}{M}}+a-\sigma \frac{(1-\tau) n}{1-\frac{\tau E}{M}}\right]}{2\left[\frac{(1-\tau) n}{1-\frac{\tau E}{M}}+a\right]} .
$$

Developing (41) further yields

$$
\left.\frac{\partial n_{t}}{\partial n_{t+1}}\right|_{n_{t}=n^{*}}=\frac{\left[1-\sigma \frac{(1-\tau) n}{(1-\tau) n+a\left(1-\frac{\tau E}{M}\right)}\right]}{2}=\frac{(1-\sigma)(1-\tau) n+a\left(1-\frac{\tau E}{M}\right)}{2(1-\tau) n+2 a\left(1-\frac{\tau E}{M}\right)} .
$$

Inverting (42) provides the following stability condition for the forward dynamics

$$
\frac{2(1-\tau) n+2 a\left(1-\frac{\tau E}{M}\right)}{(1-\sigma)(1-\tau) n+a\left(1-\frac{\tau E}{M}\right)}>-1
$$

Taking into account the fact that the denominator is negative we can re-express (43) as

$$
(\sigma-3)(1-\tau) n>3 a\left(1-\frac{\tau E}{M}\right),
$$

so that in this specification it is necessary for stability that $\sigma>3$. Since the steady state employment is a decreasing function of exemption, both sides of (44) are decreasing 
functions of exemption. If the tax rate and/or the relative luxury, $a$, are small enough, we can see that increasing the level of exemption turns around the inequality sign in (44), and makes the steady state unstable.

\section{Conclusions}

We have studied the effects of distortionary tax policy on cycles and the local stability of equilibria in a simple overlapping generations model with a balanced budget rule. In particular, we have explored the implications of the details of the tax system on these issues.

We have shown that under proportional taxation the steady state supply exceeds (falls short of) the one without taxation, if the elasticity of the marginal utility of the second period consumption, is higher (lower) than one. This is because the higher (lower) steady state supply in the presence of taxation is due to the fact that the positive income effect of the tax rate dominates (is dominated by) the negative substitution effect. Moreover, in the presence of cycles there is a critical level of tax rate such that for all higher tax rates there are no cycles in the economy. The steady state supply under progressive taxation is less than the one with proportional taxation due to the negative income effect of tax exemption on supply. In this case there is a critical level of tax exemption, such that for all smaller tax exemptions there are no cycles in the economy. Hence, a sufficiently high tax rate and low tax progression eliminate cycles.

We have also characterized the effects of tax policy on the local stability of equilibria by providing the following results. First, if the lifetime utility function is quasilinear, increasing the tax rate can cause the economy to become locally unstable both with proportional and linearly progressive taxation so that tax exemption does not matter. This is because the income effect of tax exemption is zero for consumption. Second, if the lifetime utility function is not quasi-linear, then for small tax rate an increase in progression can locally destabilize the economy. 
Appendix:

\section{Derivation of the Slutsky equation for the supply function}

Maximizing the utility function $U=u(c)-v(n)$ subject to $c=(1-\tau) n+m$, where $m$ is non-labor income, gives $U_{n}=0=u^{\prime}(c)(1-\tau)-v^{\prime}(n)$, which implicitly defines the supply function $n=n(\tau, m)$. Substituting this for $n$ in $U$ gives the indirect utility function $U^{*}(\tau, m)=U^{o}$ with the following properties: $U_{m}^{*}=u^{\prime}\left(c^{*}\right)>0$ and $U_{\tau}^{*}=-n U_{m}^{*}<0$. Given the monotone $U_{m}^{*}$ we can invert the indirect utility function for $m$ so that we have the following expenditure function, $m=h\left(\tau, U^{o}\right)$. Substituting this for $m$ in $U^{*}(\tau, m)=U^{o}$ yields the compensated indirect utility function ${ }^{19} U^{*}\left(h\left(\tau, U^{o}\right), \tau\right)=U^{o}$ with the following property $U_{m}^{*} h_{\tau}+U_{\tau}^{*}=0$ so that $h_{\tau}=-U_{\tau}^{*} / U_{m}^{*}=n$. According to the duality theorem we can write the relationship between the uncompensated and compensated supply as follows $n\left(h\left(\tau, U^{o}\right), \tau\right)=n^{c}\left(\tau, U^{o}\right)$. Differentiating this with respect to the tax rate gives $n_{\tau}+n_{m} h_{\tau}=n_{\tau}^{c}$ which can be written as the Slutsky equation $n_{\tau}=n_{\tau}^{c}-n n_{m}$, where we have the negative substitution effect, $n_{\tau}^{c}\left(=\frac{u^{\prime}(c)}{u^{\prime \prime}(c)(1-\tau)^{2}-v^{\prime \prime}(n)}<0\right)$, and the positive income effect, $-n n_{m}\left(=\frac{c u^{\prime \prime}(c)}{u^{\prime \prime}(c)(1-\tau)^{2}-v^{\prime \prime}(n)}>0\right)$. The latter (former) effect evaluated at $m=0$ dominates if $\sigma(n)>(<) 1$.

\footnotetext{
${ }^{19}$ See Diamond and Yaari (1972).
} 


\section{References}

Aiyagari, S.R. (1988): Economic Fluctuations Without Shocks to Fundamentals; Or, Does The Stock Market Dance to Its Own Music? Federal Reserve Bank of Minneapolis Quarterly Review 12 (Winter) , 824.

Attanasio, O.P. (1999): Consumption, in Taylor, J. and M. Woodford (eds): Handbook of Macroeconomics, Vol. 1B, North-Holland, Amsterdam, pp. 741-812.

Auerbach, A.J. and J.R. Hines Jr. (2001): Taxation and Economic Efficiency, NBER working paper, March.

Azariadis, C. and R. Guesnerie (1986): Sunspots and Cycles. Review of Economic Studies LIII, 725-737.

Cass, D., M. Okuno and I. Zilcha (1979): The Role of Money in Supporting the Pareto Optimality of Competitive Equilibrium in Consumption-Loan Type Models. Journal of Economic Theory 60, 277-305.

Chattopadhyay, S. and T.J. Muench (1999): Sunspots and Cycles Reconsidered. Economics Letters 63, 67-75.

Diamond, P. and M. Yaari (1972): Implications of the Theory of Rationing for Consumer Choice Under Uncertainty, American Economic Review 62, 333-343.

Farmer, R.E.A. and M. Woodford (1997): Self-Fulfilling Prophecies and the Business Cycle. Vintage Article. Macroeconomic Dynamics 1, 740-769.

Friedman, M. (1948): A Monetary and Fiscal Framework for Economic Stability. American Economic Review 38, 245-264.

Gale, D. (1973): Pure Exchange Equilibrium of Dynamic Economic Models. Journal of Economic Theory 6, 12-36.

Ghiglino, C. and M. Tvede (2000): Optimal Policy in OG Models. Journal of Economic Theory 90, 62-83.

Goenka, A. (1994): Fiscal Rules and Extrinsic Uncertainty. Economic Theory 4, 401 $-416$.

Grandmont, J-M. (1985): On Endogenous Competitive Business Cycles. Econometrica 53, 995-1045.

Grandmont, J-M. (1986a): Stabilizing Competitive Business Cycles. Journal of Economic Theory 40, 57-76.

Grandmont, J-M. (1986b): Periodic and Aperiodic Behaviour in Discrete OneDimensional Dynamical Systems. In Hildenbrand, W. and A. Mas-Colell (ed.) Contributions to Mathematical Economics, 227-265. North-Holland. Also in Benhabib J. (ed.) Cycles and Chaos in Economic Equilibrium, p.44-63. Princeton University Press 1992.

Guo, J.-T. (1999): Multiple Equilibria and Progressive Taxation of Labor income. Economics Letters 65, 97-103.

Guo, J.-T. and S.G. Harrison (2001): Tax Policy and Stability in a Model with Sectorspecific Externalities. Review of Economic Dynamics 4, 75.-89.

Guo, J.-T. and K.J. Lansing (1998): Indeterminacy and Stabilization Policy. Journal of Economic Theory 82,481-490.

Guo, J.-T. and K.J. Lansing (2001): Fiscal Policy, Increasing Returns and Endogenous Fluctuations. Macroeconomic Dynamics 6, 633-664.

Holmgren, R.A. (1996): A First Course in Discrete Dynamical Systems, $2^{\text {nd }}$ edition. 
Springer-Verlag, New York.

Koskela, E. and J. Vilmunen (1995): Tax Progression is Good for Employment in

Popular Models of Trade Union Behaviour. Labour Economics 3, 65-80.

Laffont, J.-J. (1988): Fundamentals of Public Economics. MIT Press.

Lambert, P.J. (1993): The Distribution and Redistribution of Income: A Mathematical Analysis. $2^{\text {nd }}$ edition, Manchester University Press.

Musgrave, R.A. and M.H.Miller. (1948): Built-in Flexibility. American Economic Review, 38, 122-128.

Musgrave, R.A. and T. Thin. (1948): Income Tax Progression, 1929-48. Journal of Political Economy 56, 498-514.

Sandmo, A. (1983): Progressive Taxation, Redistribution, and Labor Supply, Scandinavian Journal of Economics 85(3), 311-323.

Schmitt-Grohe, S. and M. Uribe (1997): Balanced Budget Rules, Distortionary, and Aggregate Instability. Journal of Political Economy 105, 976-1000.

Slitor, R.E. (1948): The Measurement of Progressivity and Built-In Flexibility. Quarterly Journal of Economics, 62, 309-313.

Woodford, M. (1984): Indeterminacy of Equilibrium in the Overlapping Generations Model: A $\quad$ Survey. Mimeo. Available at: http://www.princeton.edu/ woodford/Woodford84.pdf 